\title{
Impact of collaboration on Indian forensic science research: A scientometric mapping from 1975 to 2012
}

\author{
J. John Jeyasekar*, P. Saravanan ${ }^{1}$ \\ Department of Forensic Sciences (Formerly: Tamil Nadu Forensic Sciences Laboratory), Library Division, Government of Tamil Nadu, \\ Chennai, 'Department of Library Science, Lekshmipuram College of Arts and Science, Neyyoor, Kanyakumari, Tamil Nadu, India
}

\begin{abstract}
Research collaboration is an essential component of research. Researchers, as well as the policy makers, are showing increasing interest in research collaboration. Forensic Science being multidisciplinary subject collaboration is essential. This study is an attempt to quantify and visualize the research collaboration in Indian Forensic Science and also to assess the impact of research collaboration. A total of 2096 bibliographic records pertaining to Indian Forensic Science literatures published during the period 1975-2012 are retrieved from the Scopus database. These data are analyzed and visualized using MS-Excel spreadsheets, VOSviewer, and Pajek software. It is found that the International Multilateral Collaborations are associated with greater citation impact. The study also reveals that the International Cooperation Index of India in Forensic Science research is 7.68. India has the highest Affinity Index value of 34.16 in Forensic Science with the USA. A new measure of international collaboration known as Authorship AFI is also proposed based on the number of collaborating authors.
\end{abstract}

Keywords: Authorship affinity index, collaborative measures, forensic science, International cooperation index, research collaboration, scientometrics

\section{INTRODUCTION}

Research collaboration could be defined as the working together of researchers to achieve the common goal of producing new scientific knowledge. ${ }^{[1]}$ Collaboration is an essential component of research. Over recent years, there has been increasing interest among researchers and among science policy makers in the notion of research collaboration. It is widely assumed that collaboration in research is a good thing and that it should be encouraged. ${ }^{[2]}$ In an interview, Rev. Dr. Ignacimuthu states that "...-(collaboration) is what makes you move towards

*Address for correspondence:

E-mail: trijays@gmail.com

\begin{tabular}{|l|l|}
\hline \multicolumn{2}{|c|}{ Access this article online } \\
\hline Quick Response Code: & \\
\hline & Website: \\
\hline & www.jscires.org \\
\cline { 2 - 2 } & \\
\hline
\end{tabular}

path breaking research. Cooperation is also very important. No one individual today can become successful, unless he is able to get the cooperation of so many others... In India people are a little slow in understanding the implication of the industry-educational institution collaboration". ${ }^{[3]}$

John C. Brenner defines forensic as "analysis of information suitable for use in a court of law" and forensic sciences as "the application of scientific facts to legal problems; the field of science that is used in the judicial process". ${ }^{[4]}$ Some are derived from the physical, medical, and dental sciences, and the best-qualified workers specialize in the court-oriented aspects of each discipline". Saferstein

This is an open access article distributed under the terms of the Creative Commons Attribution-NonCommercial-ShareAlike 3.0 License, which allows others to remix, tweak, and build upon the work non-commercially, as long as the author is credited and the new creations are licensed under the identical terms.

For reprints contact: reprints@medknow.com

How to cite this article: Jeyasekar JJ, Saravanan P. Impact of collaboration on Indian forensic science research: A scientometric mapping from 1975 to 2012. J Sci Res 2015;4:135-42. 
defines "Forensic science is the application of science to those criminal and civil laws that are enforced by police agencies in a criminal justice system.."[5]

The Oxford English Dictionary lists one of the first uses of the phrase forensic science to describe a mixed science. Forensic science describes the science associating people, places, and things involved in criminal activities; these scientific disciplines assist in investigating and adjudicating criminal and civil cases. ${ }^{[6]}$ Since forensic sciences refer to science applied to criminal and civil law any science can be a forensic science if it has some application to justice. ${ }^{[7]} \mathrm{A}$ plethora of sciences have application to law and, therefore, we have an endless list of areas in forensic sciences starting from forensic accounting and ending with forensic zoology. In between these two are a number of specialties such as forensic art, forensic anthropology, forensic ballistics, forensic biology, forensic entomology, forensic pathology, forensic psychology, forensic odontology, forensic serology, forensic toxicology, forensic chemistry, and so on.

\section{LITERATURE REVIEW}

Beaver and Rosen studied the relationship between collaboration and productivity and concluded that collaboration enhances productivity. ${ }^{[2,8,9]}$ Katz and Martin state that on average, a paper written by multiple authors is likely to be more frequently cited and thus, has a higher impact. ${ }^{[1]}$ Narin et al., Gomez et al., Glänzel, and Schubert reported that internationally coauthored papers on average tend to have higher citation rates. ${ }^{[10-13]}$ Moed analyzed the relationship between international collaboration and citation impact focusing on bilateral international collaboration. His findings reveal whether or not international collaboration leads to higher citation rates depends on who is collaborating with whom. ${ }^{[14]}$ Glynn et al. analyzing the literature of breast cancer had concluded that high levels of international collaborations are associated with greater citation impact. ${ }^{[15]}$

\section{OBJECTIVES}

Research collaboration is a good thing and in inter-disciplinary subjects, it is a necessity. Numerous attempts have been made to bring together individual researchers. The collaboration among researchers may be at the institution level or between different institutions or with industries. Similarly, collaboration may be at the national level or international level. Here an attempt is made to quantify and assess the impact of research collaboration in the field of Indian Forensic Science. The single author papers are considered as zero collaborative ones. When two or more authors of same institution or different institutions collaborate, it is considered as national collaboration. International bilateral collaborative papers are the ones where one or more authors of another country collaborate with one or more Indian authors. International multilateral collaborative papers are the ones with authors of two or more countries collaborating with one or more Indian author. Collaboration clusters and networks are also visualized with the aid of computer algorithms.

\section{MATERIALS AND METHODS}

Bibliographic and citation data pertaining to global and Indian Forensic Science from 1975 to 2012 are retrieved from the Scopus database. Scopus is a bibliographic database containing abstracts and citations for academic journal articles. The following relational search query is used for retrieving data from the database:

TITLE-ABS-KEY (forensic) OR TITLE-ABS-KEY (criminalistics) OR TITLE-ABSKEY (crime investigation) OR TITLE-ABS-KEY (criminal investigation) OR TITLEABS-KEY (police science) OR TITLE-ABS-KEY (legal medicine) OR TITLE-ABSKEY (medical jurisprudence) AND AFFL (INDIA) AND PUBYEAR $>1974$ AND PUBYEAR <2013.

A total of 2096 bibliographic records pertaining to Indian Forensic Science literature are obtained from the Scopus database and subjected to further analysis. MS-Excel spreadsheets, VOSviewer (available at: www.vosviewer.com), and Pajek are used for analysis and visualization. VOSviewer is a software tool specifically designed for constructing and visualizing bibliometric maps, paying special attention to the graphical representation of such maps. Pajek is a program, for Windows, for analysis and visualization of large networks having some thousands or even millions of vertices. The latest version of Pajek is freely available for noncommercial use at its homepage: http://pajek.imfm.si.

\section{FINDINGS AND DISCUSSION}

\section{Authorship Pattern and Collaborative Measures}

The year-wise number of authors, total authors, and the various collaborative measures such as the collaborative index (CI), the degree of collaboration (DC), the collaborative coefficient (CC), and modified CC (MCC) of Indian Forensic Science literature are calculated and given in Table 1. 
Table 1: Authorship pattern and collaborative measures

\begin{tabular}{|c|c|c|c|c|c|c|c|c|c|c|c|c|c|c|c|c|c|c|c|c|c|}
\hline Year & $1 \mathrm{AU}$ & $2 \mathrm{AU}$ & $3 \mathrm{AU}$ & $4 \mathrm{AU}$ & $5 \mathrm{AU}$ & $6 \mathrm{AU}$ & $7 \mathrm{AU}$ & $8 \mathrm{AU}$ & $9 \mathrm{AU}$ & $10 \mathrm{AU}$ & $11 \mathrm{AU}$ & $12 \mathrm{~A}$ & $4 \mathrm{Al}$ & $9 \mathrm{AU}$ & $\begin{array}{c}\text { Total } \\
\text { papers }\end{array}$ & $\begin{array}{c}\text { Total } \\
\text { AU }\end{array}$ & $\mathrm{Cl}$ & DC & CC & MCC & $\begin{array}{c}\text { MCC- } \\
\text { CC }\end{array}$ \\
\hline 1975 & 8 & 4 & 5 & 2 & 0 & 0 & 0 & 0 & 0 & 0 & 0 & 0 & 0 & 0 & 11 & 39 & 2.05 & 0.58 & 0.3596 & 0.3691 & 0.0095 \\
\hline 1976 & 2 & 7 & 5 & 2 & 0 & 0 & 0 & 0 & 0 & 0 & 0 & 0 & 0 & 0 & 14 & 39 & 2.44 & 0.88 & 0.5203 & 0.534 & 0.0137 \\
\hline 1977 & 8 & 10 & 2 & 1 & 0 & 0 & 0 & 0 & 0 & 0 & 0 & 0 & 0 & 0 & 13 & 38 & 1.81 & 0.62 & 0.3373 & 0.3464 & 0.0091 \\
\hline 1978 & 3 & 3 & 4 & 3 & 0 & 0 & 0 & 0 & 0 & 0 & 0 & 0 & 0 & 0 & 10 & 33 & 2.54 & 0.77 & 0.4936 & 0.509 & 0.0154 \\
\hline 1979 & 2 & 7 & 4 & 0 & 0 & 0 & 0 & 0 & 0 & 0 & 0 & 0 & 0 & 0 & 11 & 28 & 2.15 & 0.85 & 0.4744 & 0.492 & 0.0176 \\
\hline 1980 & 4 & 7 & 3 & 2 & 0 & 0 & 0 & 0 & 0 & 0 & 0 & 0 & 0 & 0 & 12 & 35 & 2.19 & 0.75 & 0.4375 & 0.4504 & 0.0129 \\
\hline 1981 & 8 & 3 & 8 & 2 & 0 & 1 & 0 & 0 & 0 & 0 & 0 & 0 & 0 & 0 & 14 & 52 & 2.36 & 0.64 & 0.4167 & 0.4249 & 0.0082 \\
\hline 1982 & 6 & 10 & 7 & 0 & 1 & 0 & 0 & 0 & 0 & 0 & 0 & 0 & 0 & 0 & 18 & 52 & 2.17 & 0.75 & 0.4361 & 0.4447 & 0.0086 \\
\hline 1983 & 1 & 2 & 2 & 0 & 0 & 0 & 0 & 0 & 0 & 0 & 0 & 0 & 0 & 0 & 4 & 11 & 2.2 & 0.8 & 0.4667 & 0.5134 & 0.0467 \\
\hline 1984 & 2 & 5 & 6 & 0 & 1 & 0 & 0 & 0 & 0 & 0 & 0 & 0 & 0 & 0 & 12 & 35 & 2.5 & 0.86 & 0.5214 & 0.5367 & 0.0153 \\
\hline 1985 & 8 & 1 & 3 & 2 & 0 & 0 & 0 & 0 & 0 & 0 & 0 & 0 & 0 & 0 & 6 & 27 & 1.93 & 0.43 & 0.2857 & 0.2967 & 0.011 \\
\hline 1986 & 5 & 2 & 0 & 2 & 0 & 0 & 0 & 0 & 0 & 0 & 0 & 0 & 0 & 0 & 4 & 17 & 1.89 & 0.44 & 0.2778 & 0.2952 & 0.0174 \\
\hline 1987 & 1 & 4 & 3 & 0 & 0 & 0 & 0 & 0 & 0 & 0 & 0 & 0 & 0 & 0 & 7 & 18 & 2.25 & 0.88 & 0.5 & 0.5294 & 0.0294 \\
\hline 1988 & 2 & 3 & 3 & 0 & 0 & 0 & 1 & 0 & 0 & 0 & 0 & 0 & 0 & 0 & 7 & 24 & 2.67 & 0.78 & 0.5397 & 0.5632 & 0.0235 \\
\hline 1989 & 6 & 13 & 14 & 4 & 0 & 2 & 0 & 1 & 0 & 0 & 0 & 0 & 0 & 0 & 34 & 110 & 2.75 & 0.85 & 094 & 0.5 & 0.0047 \\
\hline 1990 & 4 & 10 & 4 & 4 & 1 & 0 & 0 & 0 & 0 & 0 & 0 & 0 & 0 & 0 & 19 & 57 & 2.48 & 0.83 & 0.4986 & 0.5075 & 0.0089 \\
\hline 1991 & 7 & 8 & 4 & 1 & 0 & 0 & 0 & 0 & 0 & 0 & 0 & 0 & 0 & 0 & 13 & 39 & 1.95 & 0.65 & 0.3708 & 0.3806 & 0.0098 \\
\hline 1992 & 1 & 10 & 4 & 1 & 4 & 0 & 0 & 0 & 0 & 0 & 0 & 0 & 0 & 0 & 19 & 57 & 2.85 & 0.95 & 0.5808 & 0.5912 & 0.0104 \\
\hline 1993 & 2 & 0 & 1 & 1 & 1 & 0 & 0 & 0 & 0 & 0 & 0 & 0 & 0 & 0 & 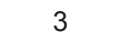 & 14 & 2.8 & 0.6 & 0.4433 & 74 & 341 \\
\hline 1994 & 0 & 1 & 1 & 0 & 1 & 0 & 0 & 0 & 0 & 0 & 0 & 0 & 0 & 0 & 3 & 10 & 3.33 & 1 & 0.6556 & 0.7284 & 0.0728 \\
\hline 1995 & 3 & 2 & 1 & 1 & 2 & 0 & 0 & 0 & 0 & 0 & 0 & 0 & 0 & 0 & 6 & 24 & 2.67 & 0.67 & 0.4463 & 0.4657 & 0.0194 \\
\hline 1996 & 6 & 3 & 3 & 0 & 1 & 0 & 0 & 0 & 0 & 0 & 0 & 0 & 0 & 0 & 7 & 26 & 2 & 0.54 & 0.3051 & 0.3173 & 0.0122 \\
\hline 1997 & 5 & 0 & 5 & 2 & 2 & 0 & 0 & 0 & 0 & 0 & 0 & 0 & 0 & 0 & 9 & 38 & 2.71 & 0.64 & 0.4595 & 0.4719 & 0.0124 \\
\hline 1998 & 7 & 6 & 3 & 4 & 0 & 0 & 0 & 0 & 0 & 0 & 0 & 0 & 0 & 0 & 13 & 44 & 2.2 & 0.65 & 0.4025 & 0.4119 & 0.0094 \\
\hline 1999 & 5 & 4 & 7 & 2 & 2 & 0 & 1 & 0 & 0 & 0 & 0 & 0 & 0 & 0 & 16 & 59 & 2.81 & 0.76 & 0.5059 & 0.5146 & 0.0087 \\
\hline 2000 & 9 & 13 & 8 & 6 & 2 & 1 & 0 & 0 & 0 & 1 & 0 & 0 & 0 & 0 & 31 & 109 & 2.73 & 0.78 & 0.4917 & 0.4963 & 0.0046 \\
\hline 2001 & 5 & 12 & 8 & 8 & 1 & 0 & 1 & 0 & 1 & 0 & 0 & 0 & 0 & 1 & 32 & 125 & 3.38 & 0.86 & 0.5629 & 0.5674 & 0.0045 \\
\hline 2002 & 9 & 17 & 17 & 6 & 5 & 3 & 0 & 0 & 0 & 0 & 0 & 0 & 0 & 0 & 48 & 161 & 2.82 & 0.84 & 0.5363 & 0.5397 & 0.0034 \\
\hline 2003 & 12 & 26 & 13 & 11 & 8 & 0 & 0 & 0 & 0 & 0 & 0 & 0 & 0 & 0 & 58 & 187 & 2.67 & 0.83 & 0.514 & 0.5168 & 0.0028 \\
\hline 2004 & 4 & 23 & 11 & 12 & 12 & 0 & 0 & 1 & 0 & 0 & 0 & 0 & 0 & 0 & 59 & 199 & 3.16 & 0.94 & 0.6081 & 0.6112 & 0.0031 \\
\hline 2005 & 15 & 19 & 23 & 5 & 5 & 4 & 1 & 1 & 0 & 0 & 0 & 0 & 0 & 0 & 58 & 206 & 2.82 & 0.79 & 0.5157 & 0.5207 & 0.005 \\
\hline 2006 & 12 & 20 & 32 & 18 & 4 & 4 & 1 & 0 & 1 & 0 & 0 & 0 & 0 & 0 & 80 & 280 & 3.04 & 0.87 & 0.5773 & 0.5794 & 0.0021 \\
\hline 2007 & 19 & 24 & 26 & 19 & 15 & 5 & 3 & 2 & 0 & 0 & 0 & 0 & 0 & 0 & 94 & 363 & 3.21 & 0.83 & 0.567 & 0.5686 & 0.0016 \\
\hline 2008 & 21 & 33 & 25 & 22 & 8 & 9 & 0 & 1 & 1 & 1 & 0 & 0 & 0 & 0 & 100 & 371 & 3.07 & 0.83 & 0.5391 & 0.5406 & 0.0015 \\
\hline 2009 & 26 & 37 & 55 & 35 & 17 & 10 & 1 & 2 & 1 & 2 & 0 & 0 & 2 & 0 & 162 & 630 & 3.35 & 0.86 & 0.5847 & 0.5856 & 0.0009 \\
\hline 2010 & 33 & 46 & 59 & 45 & 26 & 12 & 7 & 0 & 2 & 2 & 2 & 0 & 1 & 0 & 202 & 807 & 3.43 & 0.86 & 0.5893 & 0.59 & 0.0007 \\
\hline 2011 & 30 & 66 & 77 & 63 & 30 & 22 & 4 & 2 & 2 & 1 & 0 & 1 & 0 & 0 & 268 & 1011 & 3.39 & 0.9 & 0.609 & 0.6096 & 0.0006 \\
\hline 2012 & 41 & 50 & 85 & 65 & 43 & 25 & 3 & 1 & 2 & 1 & 2 & 0 & 0 & 0 & 277 & 1100 & 3.46 & 0.87 & 0.6071 & 0.6077 & 0.0006 \\
\hline Total & 342 & 511 & 541 & 351 & 192 & 98 & 23 & 11 & 10 & 8 & 4 & 1 & 3 & 1 & 2096 & 6475 & 3.09 & 0.84 & 0.5558 & 0.5559 & 0.0001 \\
\hline
\end{tabular}

$\mathrm{CI}=$ Collaborative index, $\mathrm{DC}=$ Degree of collaboration, $\mathrm{CC}=$ Collaborative co-efficient, $\mathrm{MCC}=$ Modified collaborative co-efficient

It is found from the table that the number of single author papers during the period of study is 342 . Two author papers number 511 and three author papers number 541. One paper has a maximum of 19 authors. The total authorships involved in the production of the total 2096 papers are 6475.

Many studies have been conducted to examine the authorship pattern and collaboration in a discipline, the average number of authors per paper, the proportion of single and multi-author papers, etc. Some of them are the CI, DC, CC, and MCC studies.
The expressions used in these measures are as follows:

$f_{j}$ is the number of papers having $j$ authors in collection $\mathrm{K}$

$\mathrm{N}$ is the total number of papers in $\mathrm{K}$ and $\mathrm{N}=\Sigma j f_{j}$

A is the total number of authors in collection $\mathrm{K}$.

In 1980, Lawani proposed the CI. CI is the mean number of authors per paper. ${ }^{[16]}$ It can be calculated easily, but it cannot be interpreted as a degree because it has no upper-value limit. It is denoted by the formula 


\section{No of collabration}

$$
\begin{gathered}
\text { AAFI }=\frac{\text { authors between A and B }}{\text { No of collaborating authors }} \times 100 \\
\text { links between A and rest } \\
\text { of the World }
\end{gathered}
$$

In simpler terms,

$$
\mathrm{CI}=\frac{\text { Total no of authors }}{\text { Total no of papers }}
$$

In the present study, it is found that CI was lowest (1.81) in the year 1977. CI was at the highest of 3.46 in the year 2012. Mean CI during the period of study was 3.09.

Subramanyam propounded the DC, a measure to calculate the proportion of single and multi-author papers and to interpret it as a degree. According to Subramanyam,

$$
\mathrm{DC}=\frac{N m}{N s+N m}
$$

Where $\mathrm{Nm}$ is the number of multi-author papers, and Ns is the number of single author papers. ${ }^{[17]}$ This can be expressed more simply as

DC $=\frac{\text { No of multi author papers }}{\text { Total no of papers }}$

because Ns $+\mathrm{Nm}$ give the total number of papers.

This can also be expressed as $\mathrm{DC}=1-\frac{f_{1}}{\mathrm{~N}}$

DC varies from 0 when all the papers have a single author to 1 when all the papers have more than one author. It can be easily calculated and can also be easily interpreted.

It is found in this study that DC was lowest at 0.43 in 1985 and highest at 1.00 in 1994. In 1994, all papers were multi-authored ones, hence the highest value. Mean DC during the study period was 0.84 .

Ajiferuke, Burell, and Tague gave a new measure known as $\mathrm{CC}$, which removed the shortcomings related to $\mathrm{CI}$ and DC. ${ }^{[18]} \mathrm{CC}$ is represented as:

$$
\mathrm{CC}=1-\frac{\sum \frac{A}{J}=1\left(\frac{1}{j}\right) f_{\mathrm{j}}}{N}
$$

In this study, CC was lowest in 1986, when it was 0.2778 . It was at the highest value of 0.6556 in 1994. The mean CC was 0.5558 .
Savanur and Srikanth modified the CC and derived the MCC as follows: ${ }^{[19]}$

$$
\operatorname{MCC}=\frac{A}{A-1}\left\{1-\frac{\sum \frac{A}{j}=\left(\frac{1}{j}\right) f_{\mathrm{j}}}{N}\right\}
$$

The study found MCC was lowest in 1986, when it was 0.2952 . It was at the highest value of 0.7284 in 1994 . The mean MCC during the period of study was 0.5559 .

It is also observed from the table that the mean difference between CC and MCC is 0.0001. Least difference between CC and MCC, i.e. 0.0006 is observed during the years 2011 and 2012. In these 2 years, the numbers of authors are 1011 and 1100, respectively. The highest difference CC and MCC, which is 0.0728 , is observed in 1994. In 1994, the total number of authors was 10 which is the least of all the years under study. It can be concluded that no significant difference can be observed between CC values and MCC values, and also this variation narrows down when the number of authorships increases.

The expressions for CC and MCC given by the respective proponents are studied to find the reason behind this. It is observed from these expressions that MCC is the product of and CC.

$\frac{A}{A-1}$

If value 1 is substituted for $\mathrm{A}, \mathrm{MCC}$ becomes

$\mathrm{MCC}=\frac{1}{0} \times \mathrm{CC}=\infty$

If values $2,3,4$, etc., are substituted for A, MCC follows the arithmetic progression $\frac{2}{1}$ CC, $\frac{3}{2}$ CC, $\frac{4}{3}$ CC, etc., or 2 CC, 1.5 CC, 1.33 CC, etc. Therefore, when the number of author is as low as 2, MCC has the highest value of 2 CC and the difference between CC and MCC decreases with the increase in authorship. Hence, it can be concluded that the CC and MCC values do not vary significantly for very large bibliographic data.

\section{Impact of Research Collaboration}

The various levels of collaboration, their volume, the percentage of volume, the number of publication cited (tpc), the number of citations, and the percentage of citation, citedness, citation per paper (CPP), and the relative citation index (RCI) are calculated and given in Table 2 . 
It is observed from the table that out of the 2096 research papers published from India during the study period, 342 papers are authored by a single author and do not have authorship collaboration. Hence, these zero collaboration level papers form $16.32 \%$. The national collaboration level papers form 76\%. This means 1593 papers have Indian authors collaborating either within their own institution or with other institutions. International bilateral level collaboration is observed in $1.34 \%$. This means 28 papers have an Indian author collaborating with an author of another country. More than one author of another country or one or more authors from more than one country had collaborated with an Indian author in case of 133 papers. Hence, international multilateral collaboration level papers form $6.35 \%$.

Out of the 342 zero collaboration level papers, 126 papers have received a total of 606 citations, which is $10.59 \%$ of the total citations. The volume of the different levels of research collaboration, and the publications cited and not cited can be visualized from Figure 1. The citedness, CPP, and RCI of zero collaborative papers stand at 36.84, 1.77, and 0.65 , respectively. About 711 papers out the 1593 national level collaborative papers have received citations. The number of citations received by these papers is 4466 , which is $78 \%$ of the total citations. This is the highest among the various levels of collaborative papers. However,

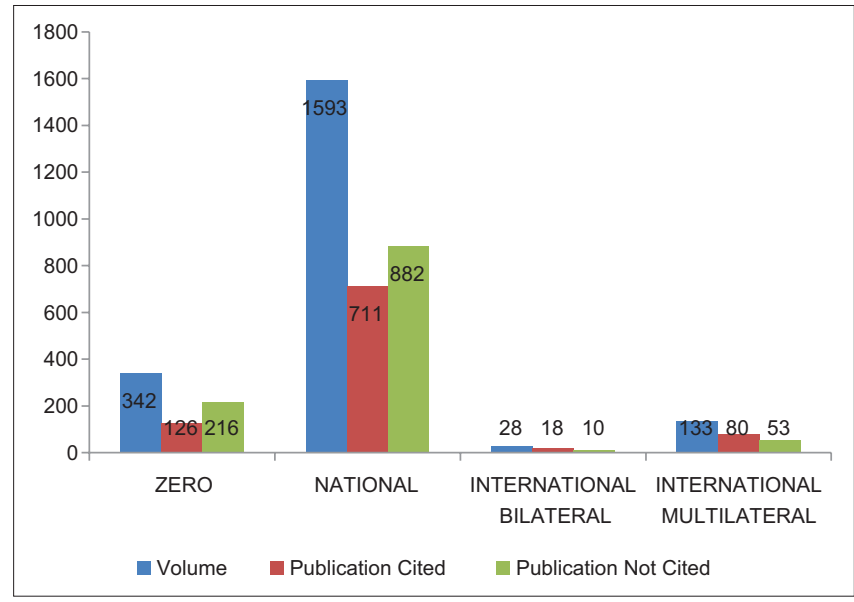

Figure 1: Volume of research collaboration citedness, CPP, and RCI values are relatively low when compared with those of international bilateral as well as multilateral collaborative papers. This is illustrated in Figure 2.

Among the 28 international bilateral papers, 18 papers have received 134 citations, which is $2.34 \%$ of the total. The citedness, CPP, and RCI values of this category are 64.29, 4.79, and 1.75, respectively. Among the international multilateral collaborative papers, 80 papers have received 519 citations, which is $9.07 \%$ of the total citations. The citedness is 44.61 , the CPP is 6.49 , and RCI is 2.38 for international multi-lateral papers.

It is found that high-level collaboration leads to high citation impact. Glynn et al. analyzed the literature of breast cancer had concluded that high levels of international collaborations are associated with greater citation impact. ${ }^{[15]}$ Hence, collaborative research, particularly among international forensic stakeholders such as the Forensic Scientists in the Laboratories, Forensic Pathologists, Forensic Odontologists, Police, Judiciary, Forensic Science academicians, etc., would definitely have a greater impact on Forensic Science research.

\section{Visualization of International Collaboration}

To enhance the visualization of the collaborating countries and their level of collaboration, a cluster map of these

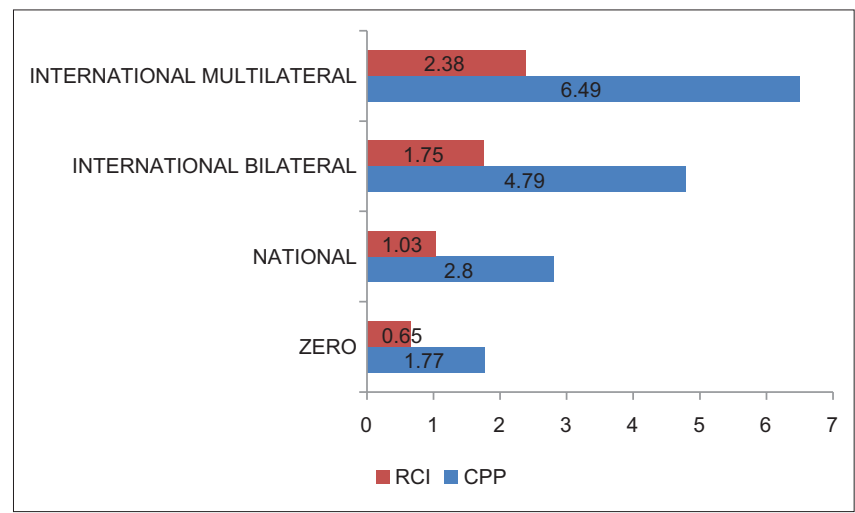

Figure 2: Citation per paper and relative citation index of research collaboration

Table 2: Volume and relative citation index of research collaboration

\begin{tabular}{lcccccccc}
\hline Collaboration & Volume & Percentage & tpc & Citation & Percentage & Citedness & CPP & RCI \\
\hline Zero & 342 & 16.32 & 126 & 606 & 10.59 & 36.84 & 1.77 & 0.65 \\
National & 1593 & 76.00 & 711 & 4466 & 78.00 & 44.63 & 2.80 & 1.03 \\
International bilateral & 28 & 1.34 & 18 & 134 & 2.34 & 64.29 & 4.79 & 1.75 \\
International multilateral & 133 & 6.35 & 80 & 519 & 9.07 & 60.15 & 6.49 & 2.38 \\
Total & 2096 & 100 & 935 & 5725 & 100 & 44.61 & 2.73 & 1.00 \\
\hline
\end{tabular}

$\mathrm{RCI}=$ Relative citation index, $\mathrm{CPP}=$ Citation per paper, $\mathrm{tpc}=$ The number of publication cited 


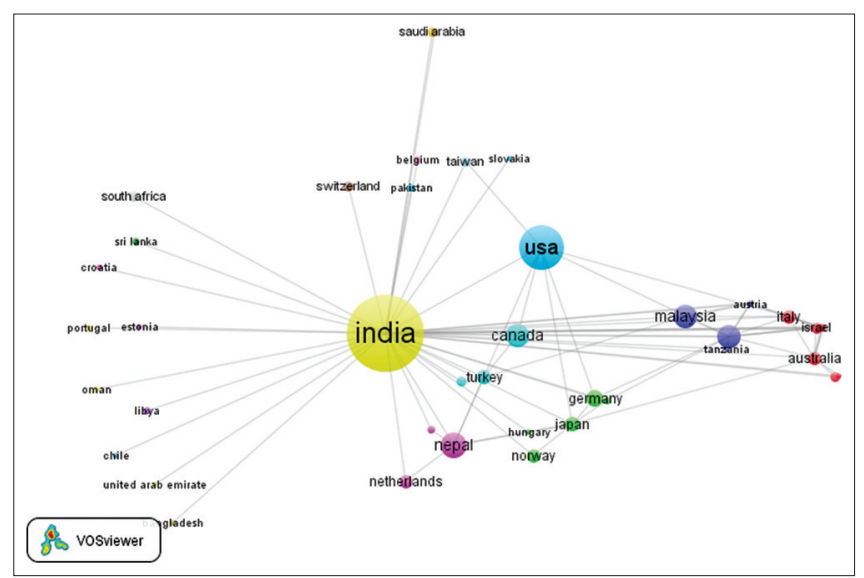

Figure 3: Cluster map of collaborating countries

is created using VOSviewer. This cluster map is given in Figure 3.

It is observed from the cluster map that there are 19 clusters, and these clusters are marked with different colors, and the weight of the labels is visualized by their size. The relational position, weight, and the cluster number obtained from VOSviewer are given in Table 3.

\section{International Cooperation Index}

Frame and Carpenter suggested the International Cooperation Index (ICI), which is also known as Internationalization Index and is based on the number of international linkages. ${ }^{[20]}$ From Table 3, it is observed that the number of international links of India in Forensic Science is 161 . The total number of papers contributed by India in Forensic Science is 2096. According to the formula given by Frame and Carpenter,

$$
\text { ICI }=\frac{161}{2096} \times 100=7.68
$$

Hence, the ICI of India in Forensic Science research is 7.68.

\section{Affinity Index}

Affinity Index (AFI) is the measure or research collaboration between countries in a given area of research. ${ }^{[21]}$ The study by Arunachalam and Doss is one of the earliest works to examine the patterns of collaboration between certain Asian and nonAsian countries. Affinity Index is the indicator used to evaluate the relative rate of scientific exchanges between one country (A) and another (B) over a given period of time and in relation to all international cooperations between the same two countries over the same period of time. It is mathematically expressed as:

$$
\begin{gathered}
\text { No of } \text { Co - operation links } \\
\text { between A and B } \\
\begin{array}{c}
\text { No of Co - operation links between } \\
\text { A and rest of the World }
\end{array}
\end{gathered}
$$

When the indicator is above 1.0, a country produces more publications in collaboration than expected based on the scientific output, while an index value below 1.0 means the reverse. The AFI of India with other countries in the field of Forensic Sciences for the study period is calculated and given in Table 3.

It is found from the table, that 26 countries have AFI value more than 1 and 16 countries have AFI $<1$. India has highest AFI in Forensic Science with the USA. The AFI value of USA is 34.16 . Hence, it is understood that the USA has the highest number collaborative research work with India in Forensic Science. Nepal comes second with AFI value of 11.18. Canada's AFI value is 9.94 whereas Malaysia and UK have the value 9.32.

\section{Authorship Affinity Index}

AFI is calculated considering the links between the collaborating countries. We propose a similar measure called Authorship AFI (AAFI) based on the number of authorships involved in the international collaborative papers. AAFI is expressed mathematically as follows:

No of collabration

$$
\text { AAFI }=\frac{\text { authors between A and B }}{\text { No of collaborating authors }} \times 100
$$

The AAFI thus calculated is also enumerated in Table 3 . It is found that 15 countries have AAFI value $>1$ and 27 countries have AAFI value $<1$. USA has the highest AAFI value of 31.76. Malaysia comes next with the value of 9.93 .

The difference between AFI and AAFI of all the collaborating countries are also calculated and given in Table 2. An examination of these values reveals that though Nepal comes second in terms of AFI, it lags Malaysia and Canada in terms of AAFI. In addition, the difference between AFI and AAFI values of Malaysia and Portugal show negative value. The reason for these is AFI is concerned with number of cooperative links whereas AAFI is concerned with the number of cooperative authors. Thus, the strength of the collaborating authors determines the AAFI. 
Table 3: Collaboration weight and affinity index

\begin{tabular}{|c|c|c|c|c|c|c|c|c|}
\hline Label & $x$ & $\mathbf{Y}$ & Binary count weight & Full count weight & Cluster number & AFI & AAFI & AFI-AAFI \\
\hline India & -0.3092 & -0.0203 & 161 & 403 & 4 & & & \\
\hline USA & 0.1552 & 0.2366 & 55 & 128 & 7 & 34.16 & 31.76 & 2.4 \\
\hline Nepal & -0.1041 & -0.3544 & 18 & 28 & 5 & 11.18 & 6.95 & 4.23 \\
\hline Canada & 0.0844 & -0.0293 & 16 & 32 & 6 & 9.94 & 7.94 & 2 \\
\hline Malaysia & 0.5872 & 0.0305 & 15 & 40 & 3 & 9.32 & 9.93 & -0.61 \\
\hline UK & 0.7166 & -0.031 & 15 & 18 & 3 & 9.32 & 4.47 & 4.85 \\
\hline Germany & 0.3161 & -0.2144 & 8 & 13 & 2 & 4.97 & 3.23 & 1.74 \\
\hline Turkey & -0.0161 & -0.1524 & 6 & 11 & 6 & 3.73 & 2.73 & 1 \\
\hline Japan & 0.2488 & -0.2918 & 6 & 15 & 2 & 3.73 & 3.72 & 0.01 \\
\hline The Netherlands & -0.2482 & -0.4607 & 5 & 5 & 5 & 3.11 & 1.24 & 1.87 \\
\hline Norway & 0.1322 & -0.3857 & 5 & 10 & 2 & 3.11 & 2.48 & 0.63 \\
\hline Australia & 0.9698 & -0.0951 & 5 & 9 & 1 & 3.11 & 2.23 & 0.88 \\
\hline Italy & 0.8916 & 0.0287 & 5 & 11 & 1 & 3.11 & 2.73 & 0.38 \\
\hline Israel & 0.9773 & -0.0033 & 4 & 10 & 1 & 2.48 & 2.48 & 0 \\
\hline Taiwan & -0.0677 & 0.4887 & 3 & 7 & 18 & 1.86 & 1.74 & 0.12 \\
\hline South Africa & -1.0611 & 0.3863 & 3 & 4 & 16 & 1.86 & 0.99 & 0.87 \\
\hline Switzerland & -0.4178 & 0.4154 & 3 & 7 & 11 & 1.86 & 1.74 & 0.12 \\
\hline Saudi Arabia & -0.1698 & 0.8761 & 3 & 4 & 8 & 1.86 & 0.99 & 0.87 \\
\hline Netherlands Antilles & -0.0821 & -0.1637 & 3 & 3 & 6 & 1.86 & 0.74 & 1.12 \\
\hline Singapore & 1.0346 & -0.1501 & 3 & 3 & 1 & 1.86 & 0.74 & 1.12 \\
\hline Sri Lanka & -1.0535 & 0.2543 & 2 & 2 & 17 & 1.24 & 0.50 & 0.74 \\
\hline Libya & -1.0186 & -0.2524 & 2 & 3 & 15 & 1.24 & 0.74 & 0.5 \\
\hline Belgium & -0.2127 & 0.4976 & 2 & 2 & 10 & 1.24 & 0.50 & 0.74 \\
\hline Pakistan & -0.2306 & 0.4126 & 2 & 2 & 7 & 1.24 & 0.50 & 0.74 \\
\hline Egypt & -0.1717 & -0.3091 & 2 & 3 & 5 & 1.24 & 0.74 & 0.5 \\
\hline China & 0.3535 & -0.2228 & 2 & 3 & 2 & 1.24 & 0.74 & 0.5 \\
\hline Spain & 0.9892 & -0.0041 & 2 & 4 & 1 & 1.24 & 0.99 & 0.25 \\
\hline UAE & -0.9958 & -0.4733 & 1 & 1 & 19 & 0.62 & 0.25 & 0.37 \\
\hline Estonia & -1.0419 & -0.0022 & 1 & 1 & 14 & 0.62 & 0.25 & 0.37 \\
\hline Croatia & -1.163 & 0.1769 & 1 & 1 & 13 & 0.62 & 0.25 & 0.37 \\
\hline Chile & -1.1126 & -0.386 & 1 & 1 & 12 & 0.62 & 0.25 & 0.37 \\
\hline Bangladesh & -0.942 & -0.5861 & 1 & 2 & 9 & 0.62 & 0.50 & 0.12 \\
\hline Greece & -0.1633 & 0.878 & 1 & 1 & 8 & 0.62 & 0.25 & 0.37 \\
\hline Slovakia & 0.0609 & 0.5005 & 1 & 1 & 7 & 0.62 & 0.25 & 0.37 \\
\hline Oman & -1.1714 & -0.1884 & 1 & 1 & 4 & 0.62 & 0.25 & 0.37 \\
\hline Portugal & -1.1933 & -0.0036 & 1 & 3 & 4 & 0.62 & 0.74 & -0.12 \\
\hline Austria & 0.7803 & 0.0675 & 1 & 1 & 3 & 0.62 & 0.25 & 0.37 \\
\hline Fiji & 0.7805 & 0.0707 & 1 & 1 & 3 & 0.62 & 0.25 & 0.37 \\
\hline Tanzania & 0.7106 & -0.0686 & 1 & 1 & 3 & 0.62 & 0.25 & 0.37 \\
\hline Hungary & 0.1191 & -0.3153 & 1 & 1 & 2 & 0.62 & 0.25 & 0.37 \\
\hline New Zealand & 1.0434 & -0.1473 & 1 & 1 & 1 & 0.62 & 0.25 & 0.37 \\
\hline Sweden & 0.9978 & -0.0025 & 1 & 1 & 1 & 0.62 & 0.25 & 0.37 \\
\hline Uruguay & 0.9974 & -0.007 & 1 & 1 & 1 & 0.62 & 0.25 & 0.37 \\
\hline
\end{tabular}

AFI=Authorship affinity index, AAFI=Authorship affinity index

\section{Network Map of Collaborating Countries}

The map created with the aid of VOSviewer is converted into a network map with Pajek and given in Figure 4. The figure shows 43 vertices, each indicating a collaborating country. The collaboration or link strength is also indicated in the connecting lines. The vertices are arranged alphabetically.

\section{CONCLUSION}

It is found from the study that the difference between CC and MCC decreases with the increase in authorship and hence it is concluded that the CC and MCC values do not vary significantly for very large bibliographic data. International multilateral collaborations are associated with greater citation impact. The study reveals that the 


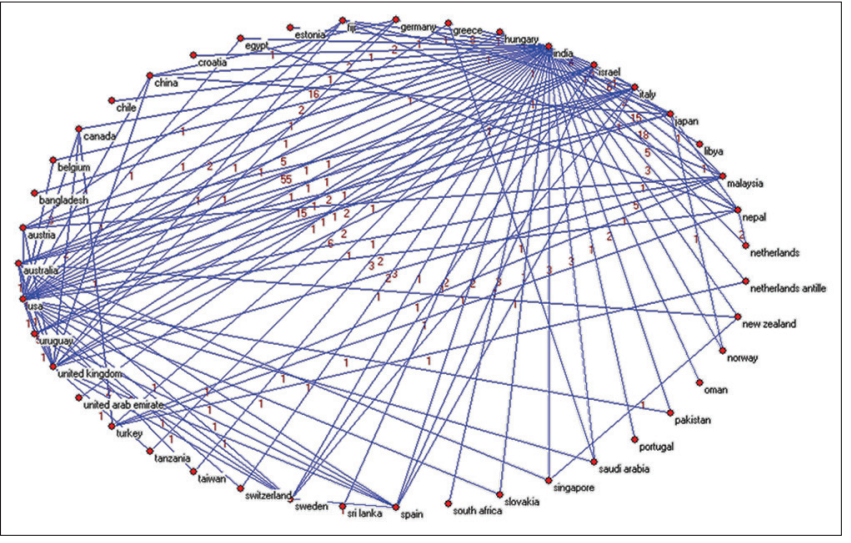

Figure 4: Network map of collaborating countries

ICI of India in Forensic Science research is 7.68. India has the highest AFI value of 34.16 in Forensic Science with the USA.

\section{Financial Support and Sponsorship}

Nil.

\section{Conflicts of Interest}

There are no conflicts of interest.

\section{REFERENCES}

1. Katz JS, Martin BR. What is research collaboration? Res Policy 1997;26:1-18.

2. Beaver D, Rosen R. Studies in scientific collaboration. Part I. Scientometrics 1978;1:65-84.

3. Dharmapalan B. To be successful in science one needs to follow a disciplined way of life - Dr. Ignacimuthu. Sci Rep 2014;51:42-4.

4. Brenner JC. Forensic Science: An Illustrated Dictionary. Boca Raton: CRC Press; 2003.

5. Saferstein R. Criminalistics: An Introduction to Forensic Science. $7^{\text {th }}$ ed. New Jersey: Prentice-Hall; 1995.

6. Houck MM, Siegel JA. Fundamentals of Forensic Science. Amsterdam: Academic Press; 2006.

7. Siegel JA, Mirakovits K. Forensic Science: The Basics. $2^{\text {nd }}$ ed. Boca Raton: CRC Press; 2010.

8. Beaver D, Rosen R. Studies in scientific collaboration. Part II. Scientometrics 1979;1:133-49.

9. Beaver D, Rosen R. Studies in scientific collaboration. Part III. Scientometrics 1979;1:231-45.

10. Narin F, Stevens K, Whitlow E. Scientific co-operation in Europe and the citation of multinationally authored papers. Scientometrics 1991;21:313-23.

11. Gomez I, Fernandez MT, Mendez A. Collaboration patterns of Spanish scientific publications in different research areas and disciplines. In: Koenig ME, editor. Proceedings of the Biennal Conference of the International Society for Scientometrics and Informetrics. New Jersey: Learned Information; 1995. p. 187-96.

12. Glänzel W, Schubert A. Double effort=Double impact? Scientometrics 2001;50:199-214.

13. Glänzel W, Schubert A. Analysing scientific networks through co-authorship. In: Moed HF, editor. Handbook of Quantitative Science and Technology Research. London: Kluwer Academic Publication; 2004. p. 257-76.

14. Moed H. Citation Analysis in Research Evaluation. Dordrecht: Springer; 2005.

15. Glynn RW, Scutaru C, Kerin MJ, Sweeney KJ. Breast cancer research output, 1945-2008: A bibliometric and density-equalizing analysis. Breast Cancer Res 2010;12:R108.

16. Lawani SM. Quality, Collaboration and Citations in Cancer Research: A 268 Bibliometric Study. Ph.D. Dissertation, Florida State University; 1980.

17. Subramanyam K. Bibliometric studies of research collaboration: A review. J Inf Sci 1983;6:33-8

18. Ajiferuke I, Burell O, Tague-Sutcliffe J. Collaborative coefficient: A single measure of the collaboration in research. Scientometrics 1988;14:421-33.

19. Savanur K, Srikanth R. Modified collaborative coefficient: A new measure for quantifying the degree of research collaboration. Scientometrics 2010;84:365-71.

20. Frame JD, Carpenter MP. International research collaboration. Soc Stud Sci 1979;9:481-97.

21. Arunachalam S, Doss MJ. Mapping international collaboration in science in Asia through coauthorship analysis. Curr Sci 2000;79:621-8. 